\title{
In Sloterdijks Weltinnenraum Ein Konferenzbericht
} Jan Trna

Zwei Jahre nach der internationalen Tagung In memoriam Odo Marquard fand am 19. April 2017 eine ähnlich konzipierte Veranstaltung statt, die sich als deren Fortsetzung verstand und ebenfalls gemeinsam vom Lehrstuhl für Philosophie und vom Institut für Germanistik, Nordistik und Nederlandistik organisiert wurde. Das Gedenken an Marquard wurde dabei von einem Jubiläum abgelöst: 2017 feierte Peter Sloterdijk, dessen umfangreiches Werk zu einer tiefgreifenden Auseinandersetzung geradezu auffordert, seinen 70. Geburtstag. Dutzende Buchveröffentlichungen, und deren zahlreiche Übersetzungen, brachten dem in Karlsruhe geborenen und zurzeit auch dort lehrenden Philosophen einen Ruhm ein, der keineswegs lediglich auf den deutschsprachigen, ja nicht einmal den europäischen Raum zu begrenzen ist. Trotz des sowohl in Fachkreisen als auch in der breiten Öffentlichkeit hohen Bekanntheitsgrads, muss zugleich betont werden, dass das Echo, das Sloterdijk hervorzurufen versteht, oftmals eher ins Negative abdriftet. Kaum ein Denker der Gegenwart wird so umstritten und kontrovers diskutiert wie Sloterdijk. Dennoch ließ sich die Tagung In Sloterdijks Weltinnenraum auf die erwartbaren Szenarien, nämlich eine bloße unkritische Feier seiner Leistungen oder im Gegenteil eine Anprangerung seiner Entgleisungen, nicht ein.

Auch diesmal verdiente die Konferenz das Attribut international, denn die Vortragenden trafen nicht nur aus Tschechien, sondern auch aus Bosnien-Herzegowina, Deutschland, Großbritannien, Österreich und den Niederlanden ein. Ebenso wurde man Sloterdijks wissenschaftlicher Ausrichtung gerecht, weil Philosophen sowie Germanisten zugegen waren. Die Skala der vorgetragenen Themen umspannte seine gesamte Schaffensperiode; von seinen frühen Schriften bis zu seinem Spätwerk.

Nach einem zweisprachigen Grußwort in Deutsch und Tschechisch, das von den Veranstaltern Aleš Urválek (ÚGNN) und Radim Brázda (KFI) gehalten wurde, wurde die Tagung mit Beiträgen der beiden Präsentierenden (in obiger Reihenfolge) in tschechischer Sprache eröffnet. Obwohl die restlichen Beträge auf Deutsch waren, stand dem 
gemischten tschechisch-deutschsprachigen Publikum jeweils eine schriftliche Vorlage in der anderen Sprache zur Verfügung, Nachfragen wurden gedolmetscht.

In seinem Beitrag „Nicht ganz schlecht für einen Philosophen“. Sloterdijk als Kenner der deutschsprachigen Literatur versucht Urválek zu ergründen, mit welchem Gewinn der Autor für einen Germanisten gelesen werden kann. Brázda betrachtet dagegen Sloterdijks philosophische Kompetenz, mit literarischen Texten produktiv zu arbeiten. In Sloterdijk und das Kabinett der Philosophie, so der Titel seiner Präsentation, beschreibt Brázda das imaginative Verfahren, welches Sloterdijk bezüglich Nachtwachen von Bonaventura ergreifen könnte.

Wolfgang Müller-Funk, Professor der Wiener Universität, behandelt in dem Beitrag Die Weimarer Republik - ein historisches Hauptstück der zynischen Vernunft. Die narrative Formatierung der deutschen Zwischenkriegszeit in Peter Sloterdijks kulturgeschichtlichem Kompendium von 1983 Sloterdijks Schlüsselwerk Kritik der zynischen Vernunft (1983), indem er sich mit den, nach seinen Worten, künstlichen Gegenpositionen, nämlich dem Zynismus und Kynismus, auseinandersetzt.

Iwona Janicka, die an der Universität Warwick tätig ist, referiert Über das Astronomische und das Mikroskopische: Sloterdijk und die Frage der Geschichte, wobei sie das Verhältnis Sloterdijks Philosophie zu neuen philosophischen Trends auslotet.

Sjoerd van Tuinen, wissenschaftlicher Mitarbeiter am Lehrstuhl für Philosophie an der Universität Rotterdam, bringt in seinem Referat Sloterdijk und die beste aller möglichen Welten die Auffassung des Optimismus näher, die Sloterdijk in seinem Tagebuch Zeilen und Tage. Notizen 2008-2011 formulierte, und zieht Parallelen zu G. W. Leibniz.

Anthropoontologisches bei Sloterdijk lautet der Beitragstitel des Würzburger Professors Wolfgang Riedel, der sich vor allem auf Sloterdijks dreibändiges Opus magnum Sphären bezieht, bei dem er sich vornehmlich dem ersten Band Blasen widmet.

Břetislav Horyna aus Brno nimmt in seinem Vortag Die postfaktische Welt der Analphabetenwahrheiten u.a. die ökonomische Theorie von Sloterdijk ins Visier, hinterfragt sie, um schließlich festzustellen, dass Sloterdijk heutzutage lediglich Sloterdijk'sche Wahrheiten ausbreitet, ohne darüber diskutieren zu wollen.

Der an der Universität Sarajevo wirkende Professor Vahidin Preljević nimmt in dem Beitrag Selbstoptimierungen. Literatur und Anthropotechnik in Peter Sloterdijks Schriften vor allen Dingen das Buch Du musst dein Leben ändern in den Fokus.

Wie eingangs erwähnt, lässt sich Peter Sloterdijks Tätigkeit nicht auf ein einziges Gebiet beschränken, sie entfaltet sich themen- und fachübergreifend, wobei der Autor mit vorrückendem Alter bei der Themenwahl immer mehr Freiheit beansprucht, als öffentlicher Intellektueller agiert und auf die brennenden, nicht selten heiklen Fragen direkte Antworten liefert. Trotzdem oder gerade deshalb wird er zwar stark rezipiert, in mancher Hinsicht aber nicht genug ernstgenommen. Veranstaltungen wie In Sloterdijks Weltinnenraum stellen sowohl im tschechischen als auch im deutschen Kontext eine Ausnahme dar.

Im Großen und Ganzen leistete die Konferenz einen wichtigen Beitrag zur Erforschung des Werks eines der einflussreichsten Intellektuellen der Gegenwart. Die Fortset- 
zung der zweijährigen Symposien-Tradition ist vorgesehen, 2019 soll Hans Blumenberg auf dem Programm stehen.

Mgr. Jan Trna / 383309@mail.muni.cz

Masarykova univerzita, Filozofická fakulta, Ústav germanistiky, nordistiky a nederlandistiky Arna Nováka 1, 60200 Brno, CZ 
